\title{
Conotruncal heart malformations in Egypt: An epidemiological study
}

\author{
Doa'a A. Saleh ${ }^{1}$, Sameera Ezzat ${ }^{2}$, Hala Hamza ${ }^{1}$, Mohamed Abdel-Hamid ${ }^{3}$, Karen S. Kuehl ${ }^{4}$, \\ Christopher A. Loffredo ${ }^{5^{*}}$
}

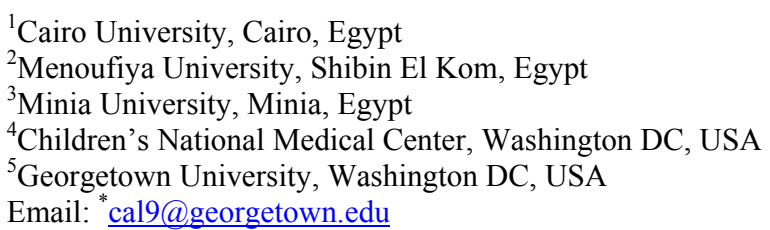

Received 23 July 2013; revised 23 August 2013; accepted 30 August 2013

Copyright (C) 2013 Doa'a A. Saleh et al. This is an open access article distributed under the Creative Commons Attribution License, which permits unrestricted use, distribution, and reproduction in any medium, provided the original work is properly cited.

\begin{abstract}
Conotruncal malformations of the heart are a major category of birth defects. No previous epidemiological studies on these malformations have been carried out in Egypt; therefore our study aimed to describe associations with maternal and infant factors in order to identify possible risk factors. Cases $(\mathrm{N}=255)$ were children up to two years of age whose heart malformations were confirmed by echocardiography; they were enrolled at the Cardiology Department of the Pediatric Hospital of Cairo University. Controls ( $\mathbf{N}=$ 155) were free of congenital heart malformations, matched to the cases by age, and recruited from outpatients of the same hospital. Mothers of cases (97\%) and controls $(89 \%)$ provided consent to participate in an interview about their medical, familial, and occupational histories. Odds ratios (OR) and exact 95\% confidence intervals (CI) assessed the magnitude and statistical significance of case-control differences. Cases were divided into two groups based on the presence of d-transposition of the great arteries (TGA): there were 139 with TGA and 116 with normally-related great arteries (NGA). Maternal diabetes prevalence was elevated in both the TGA (OR = 3.4) and NGA $(O R=5.5)$ subgroups. Several agricultural factors were associated with increased risk: raising animals (for TGA: OR = 2.4, 95\% CI 1.2 - 4.6), raising poultry (for NGA: OR = 1.8, 95\% CI 1.1 - 3.2), and using chemical rodenticides (for all conotruncal cases: OR $=3.2,95 \%$ CI $1.1-13.2)$. These results are consistent with previous studies of associations of maternal dia-
\end{abstract}

${ }^{*}$ Corresponding author. betes and pesticide exposure with conotruncal malformations. Further research is warranted to explore such associations and determine avenues for prevention.

Keywords: Congenital Heart Disease; Cardiovascular Malformations; Conotruncal Malformations; Epidemiology; Environmental Factors; Diabetes

\section{INTRODUCTION}

Congenital cardiovascular malformations (CCVM) are defects of the heart that are present at birth. They are among the most prevalent structural birth defects and are the leading cause of death among infants with birth defects, accounting for nearly one third of such deaths [1]. Conotruncal heart malformations in particular are structural abnormalities of the outflow tract of the heart, encompassing a wide array of phenotypes, the most prevalent of which are tetralogy of Fallot (TOF) and transposition of the great arteries (TGA). They are potentially life-threatening conditions, often requiring surgical intervention [2].

In the Baltimore Washington Infant Study (BWIS), the largest epidemiological study of CCVM to date, conotruncal heart defects were classified into two main subgroups, namely with and without TGA [3], and in subsequent analyses the individual phenotypes were separately assessed. The BWIS classification of TGA included cases with intact ventricular septum (IVS), ventricular septal defect (VSD), double outlet right ventricle (DORV), or complex phenotypes with pulmonary or tricuspid atresia. The group of outflow tract defects with normally related great arteries (NGA) included TOF, 
DORV, truncus arteriosus, and several rare phenotypes. The statistical analysis of potential risk factor associations revealed considerable heterogeneity across these groupings of conotruncal malformations, confirming the usefulness of a classification system based on the presence or absence of TGA $[3,4]$.

In the BWIS, conotruncal heart defects represented $14.5 \%$ of total CCVM cases in a population-based study, and their combined prevalence was 7.1 per 10,000 live births [3]. Other regional registries have reported similar figures [5], but in much of the world there are no registries to track and report occurrence rates. This situation is particularly striking in developing countries, where the magnitude of the public health problem of CCVM remains largely unknown. A study conducted in one Egyptian maternity hospital, for example, reported CCVM in 95 of $3000(3.2 \%)$ hospital births [6]. Given the 1.9 million births per year in Egypt, such an estimate would predict a large number of patients with CCVM generally and conotruncal anomalies specifically. Since conotruncal heart malformations require intensive interventions, with high costs that the public health system of a country with limited resources can ill afford, prevention and control strategies are urgently needed to relieve this burden on individuals, families, and society.

Previous studies have presumed a multifactorial model for conotruncal malformations, with both genetic [7] and non-inherited, potentially modifiable factors [8] as their causes. Maternal diabetes was previously found to be associated with the development of conotruncal malformations, especially those with normally related great arteries $(\mathrm{OR}=6.6,95 \%$ CI 3.2 - 13.3) [9], while rodenticidal chemicals were associated with the development of TGA $(\mathrm{OR}=4.7,95 \%$ CI 1.4 - 12.1) [10]. To our knowledge, such studies have not been conducted in Egypt. In this epidemiological case-control study, we assessed potential risk factor associations for conotruncal heart malformations in Egypt.

\section{METHODS}

\subsection{Subject Recruitment and Interviews}

This study was a hospital based case-control study conducted at the Pediatric Hospital of Cairo University, Egypt, under the clinical supervision of a pediatric cardiologist (H.H.). It was approved by the institutional review boards of Cairo University Hospital and of Georgetown University. Interviews were conducted with mothers of cases with conotruncal heart malformations and with mothers of controls without conotruncal heart malformations. Mothers were approached by the interviewers at the clinic, were invited to join the study, and were asked to provide informed consent. The informed consent included the mother's agreement to conduct a brief interview, to donate a sample of cells from inside her mouth (buccal cells) and the mouth of her child by oral brush, and to provide a few drops of blood by thumb prick of the mother and by heel prick of the child.

Details of the recruitment, eligibility, and participation of cases and controls are shown in Figure 1. Cases were infants and children up to the age of 2 years diagnosed with conotruncal (outflow tract) types of CCVM. The controls were infants and children free from congenital heart defects; they were recruited during the same time period as the cases, from the outpatient clinic of the same hospital, and were frequency matched to cases by age category ( 1 - 3 months, 4 - 12 months, >12 months).

The classification of the cases was reviewed by the consulting pediatric cardiologist (K.S.K.). Malformations of the cardiac outflow tract were divided for statistical analysis into those with d-transposition of great arteries (TGA) or with normally related great arteries (NGA). The TGA group consisted of cases with or without ventricular septal defect (VSD), pulmonary atresia, tricuspid atresia, or double outlet right ventricle (DORV). The NGA group included aortic-pulmonary window, supracristal VSD, DORV without TGA, common arterial trunk, and TOF.

\subsection{Data Collection}

Mothers were interviewed at the hospital by trained interviewers using a structured questionnaire, which was modeled on the instrument used in the Baltimore-Washington Infant Study [3]. It was translated into Arabic and modified to be culturally relevant for the Egyptian population. The questionnaire included the following areas of inquiry: socio-demographic factors; expected and actual date of the child's birth; child factors (sex, plural birth, birthweight, place of delivery, and any associated congenital conditions); familial birth disorders (type and specific relative who was affected); environmental exposure during the pregnancy, including acute or chronic illnesses, medications, personal habits, and the husband's habits (alcohol, drugs, or smoking); and any occupational or household exposures to chemicals or pesticides. The critical window for environmental exposure was defined as the period from 3 months before pregnancy through the first trimester.

\subsection{Statistical Analysis}

We compared cases and controls for possible differences in the questionnaire variables. Chi-square tests were performed to screen categorical variables for statistical significance, and Fisher's exact test was performed if $25 \%$ or more of the cells had expected counts less than 5 . The Student's t-test evaluated continuous variables for association with case-control status. P-values less than 0.05 


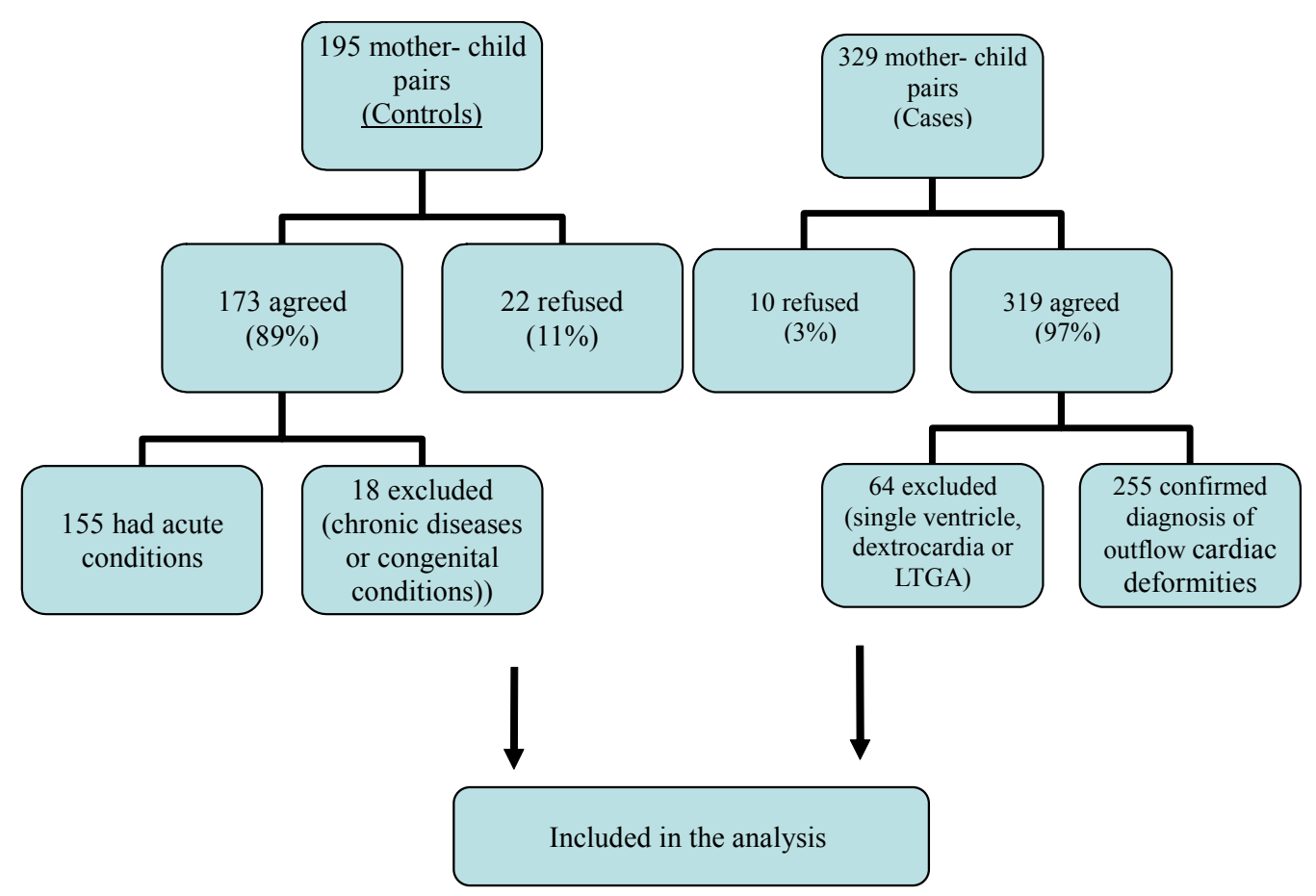

Figure 1. Recruitment of cases and controls.

were considered statistically significant. Odds ratios and 95\% confidence intervals were then calculated as measures of association and statistical significance, respectively, for each of the associations detected above, in each of the cardiac diagnostic groups separately, and in an analysis that combined all cases into one group. Due to the small sample size of several subgroups, exact confidence intervals were calculated for every association reported here, using StatXact software (Cytel Software Corp., Cambridge, MA).

\section{RESULTS}

\subsection{Study Population}

A total of 255 infants with conotruncal heart malformations and 155 controls were enrolled in the study and analyzed for statistical associations with potential risk factors (Figure 1). There were 139 infants in the TGA group and 116 in the NGA group. The diagnostic subdivisions of these cases are shown in Table 1. Within the TGA group there were 60 cases with VSD (6 of whom also had either pulmonary or tricuspid atresia), and 60 with an IVS and no intracardiac defects. Other cases included in the TGA group were 16 with DORV, 1 with pulmonary atresia, and 2 with tricuspid atresia. The NGA group was dominated by TOF $(\mathrm{n}=76)$, among which 63 cases had pulmonic stenosis and 13 had pulmonary atresia. There were also 32 cases with DORV, 6 with common arterial trunk, 1 with aortic-pulmonary window, and 1 with supracristal VSD.
Table 1. Distribution of cardiac outflow tract anomalies.

\begin{tabular}{ccc}
\hline Diagnosis & Number & Percent \\
\hline $\begin{array}{c}\text { Transposed Great } \\
\text { Arteries (TGA group) }\end{array}$ & $\mathbf{1 3 9 / 2 5 5}$ & $\mathbf{5 4 . 5 1}$ \\
Ventricular Septal Defect: & $60 / 139$ & 43.17 \\
And Tricuspid Atresia & $5 / 60$ & 8.33 \\
And Pulmonary Atresia & $3 / 60$ & 5.00 \\
Intact Ventricular Septum & $60 / 139$ & 43.17 \\
Double-outlet right ventricle & $16 / 139$ & 11.51 \\
Tricuspid Atresia & $2 / 139$ & 1.44 \\
Pulmonary Atresia & $1 / 139$ & 0.72 \\
Normally Related Great & $\mathbf{1 1 6 / 2 5 5}$ & $\mathbf{4 5 . 4 9}$ \\
Arteries (NGA group) & $76 / 116$ & 65.52 \\
Tetralogy of Fallot: & $63 / 76$ & 82.89 \\
With Pulmonary Stenosis & $13 / 76$ & 17.11 \\
With Pulmonary Atresia & $32 / 116$ & 27.59 \\
Double-Outlet Right Ventricle & $6 / 116$ & 5.17 \\
Common Arterial Trunk & $1 / 116$ & 0.86 \\
$\begin{array}{c}\text { Aortic-Pulmonary Window } \\
\text { Supracristal VSD }\end{array}$ & $1 / 116$ & 0.86 \\
\hline
\end{tabular}

\subsection{Infant Characteristics}

Among the total group of 255 cases, 8 (3.1\%) occurred 
in twin births: $5(3.6 \%)$ from the TGA group, and 3 (2.6\%) from the NGA group, compared to 7 of 154 controls $(4.5 \%)$. Six mothers of cases and six mothers of controls reported the co-twin sex: 4 with different sex (2 in TGA with VSD, 2 in TGA with IVS) and 2 with same co-twin sex among cases ( 1 in TOF, 1 in common arterial trunk), compared to 1 different and 5 same co-twin sex among controls. Different co-twin sex (4/4) was significantly associated with the TGA group $(\mathrm{p}=0.048)$ compared to the controls $(1 / 5)$.

Table 2 shows characteristics of the recruited motherinfant pairs for the major groups of TGA and NGA and their subsets, in comparison to controls. Maternal age distribution and urban vs. rural area of residency were similar across all groups. Male predominance was found in almost all case subsets compared to controls and was greatest in TGA with IVS (75\% males vs. $59 \%$ of cases; $\mathrm{p}=0.045$ ). Gestational age and birthweight were reported by $92 \%$ and $53 \%$ of the mothers of cases and controls respectively. Among those who reported the information, prematurity was associated with non-significant elevations in the odds ratios for the TGA group, TGA with DORV, and DORV with NGA. Low birthweight $(\leq 2500 \mathrm{~g})$ was not significantly associated with any of the case subsets.

Mothers of eleven of the cases reported that the child had other associated congenital anomalies; 4 (2.9\%) from the TGA group and 7 (6\%) from NGA group.
Congenital defects included: four with blood disorders (one in a case of TGA with IVS and in three with NGADORV), two with limb deformities (one NGA-DORV and one TOF), one with congenital blindness (TGA with VSD), one with cleft palate (TOF), one with hypothyroidism (NGA-DORV), one with a hydrocele (TGA and VSD), and one with a brain anomaly (TGA with IVS).

\subsection{Maternal Illnesses and Conditions}

Among all the cases, six mothers (2.4\%) reported having congenital anomalies, compared to one mother of a control $(0.6 \%)$. Three of the mothers of cases had CCVM themselves, compared to a single control. Maternal CCVM was significantly associated with the risk of having a child with NGA-DORV. Having other family members or other siblings with congenital disorders was not significantly associated with any of the conotruncal anomalies.

Overt (or preexisting) diabetes, with or without insulin or oral hypoglycemic treatment, was associated with the TOF subgroup (OR $=8.6,95 \%$ CI 0.8 - 424.0), as shown in Table 3. The odds ratio for diabetes was also elevated in several other groups (i.e. the TGA group and all its subsets), but the small numbers of exposed cases resulted in wide confidence intervals. The absence of treated controls precluded case-control comparisons on this characteristic.

Table 2. Characteristics of the mothers and infants.

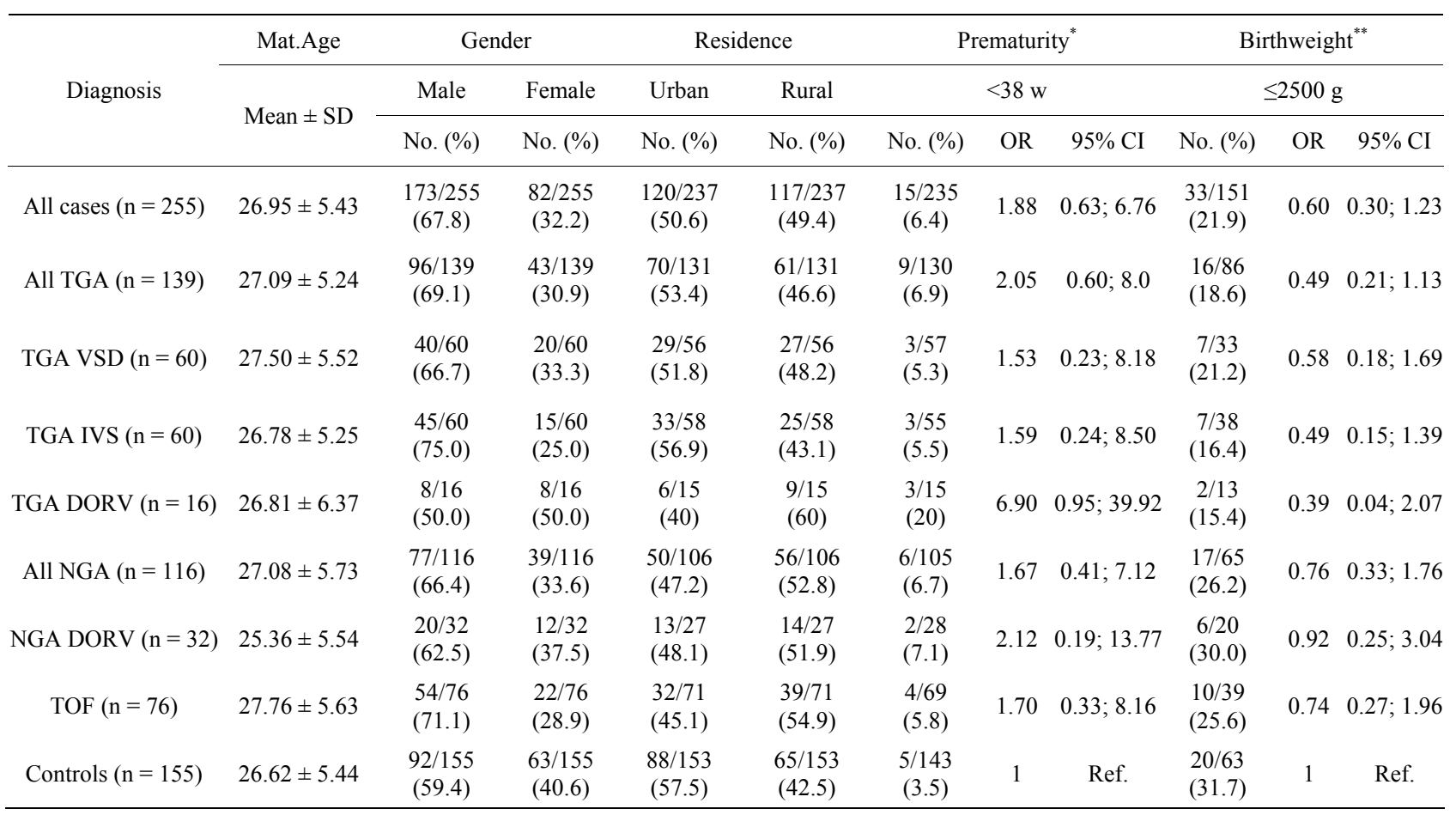

*Data missing for prematurity: 9 TGA, 11 NGA, and 12 controls. ${ }^{* *}$ Data missing for birthweight: 53 TGA, 51 NGA, and 92 controls. 
Table 3. Maternal diabetes associations with conotruncal heart malformations in their infants.

\begin{tabular}{|c|c|c|c|c|c|c|}
\hline \multirow{2}{*}{ Diagnosis } & \multicolumn{3}{|c|}{ Overt diabetes } & \multicolumn{3}{|c|}{ Treated diabetes } \\
\hline & No. $(\%)$ & OR & $95 \% \mathrm{CI}$ & No. (\%) & OR & $95 \% \mathrm{CI}$ \\
\hline All cases $(n=255)$ & $7 / 255(2.7)$ & 4.35 & $0.55 ; 197.2$ & $6 / 255(2.4)$ & - & - \\
\hline All TGA $(n=139)$ & $3 / 139(2.2)$ & 3.40 & $0.27 ; 179.5$ & $3 / 139(2.2)$ & - & - \\
\hline TGA VSD $(n=60)$ & $1 / 60(1.7)$ & 2.61 & $0.03 ; 206.2$ & $1 / 60(1.7)$ & - & - \\
\hline TGA IVS $(n=60)$ & $1 / 60(1.7)$ & 2.61 & $0.03 ; 206.2$ & $1 / 60(1.7)$ & - & - \\
\hline TGA DORV $(n=16)$ & $1 / 16(6.3)$ & 10.27 & $0.12 ; 810.8$ & $1 / 16(6.3)$ & - & - \\
\hline All NGA $(n=116)$ & $4 / 116(3.4)$ & 5.50 & $0.53 ; 272.6$ & $3 / 1162.6$ & - & - \\
\hline NGA DORV $(\mathrm{n}=32)$ & $0 / 32(0)$ & - & - & $0 / 32(0)$ & - & - \\
\hline NGA TOF $(\mathrm{n}=76)$ & $4 / 76(5.3)$ & 8.56 & $0.82 ; 424.0$ & 3/73 3.9 & - & - \\
\hline Controls $(\mathrm{n}=155)$ & $1 / 155(0.6)$ & 1 & Reference & $0 / 155(0)$ & & \\
\hline
\end{tabular}

Neither fever, bleeding during pregnancy, nausea or vomiting, thyroid disease, urinary tract infection, asthma, nor pneumonia were significantly associated with case status in this study (data not shown). A statistically significant association with hypertension was detected for TGA with DORV (OR $=4.57,95 \%$ CI 1.20 - 15.75), but not when the analysis was restricted to those receiving treatment. Similarly, having a weight problem during the critical period was reported by $14.4 \%$ of TGA group vs. $6.5 \%$ of controls, but receiving treatment was not significantly associated with any of the case subsets. This same pattern of results was observed for self-reported headache symptoms and the common cold: none remained statistically significant when the analysis was restricted to those who received medical treatment.

\subsection{Environmental Exposure}

None of the mothers were self-reported tobacco smokers. Neither paternal smoking characteristics nor maternal exposure to environmental tobacco smoke were associated with elevated risk of having a child with conotruncal anomalies. As expected in this majority Muslim society, none of the mothers reported drinking alcohol.

Table 4 shows potential environmental risk factors that were associated with one or more types of cases. Maternal exposure to rodenticidal chemicals was significantly associated with elevated risk of all conotruncal cases combined (OR $=3.21,95 \%$ CI 1.05 - 13.15). Raising animals, especially poultry (chickens, ducks, or pigeons), was significantly associated with both the TGA group $(\mathrm{OR}=1.71,95 \% \mathrm{CI} 1.02-2.88)$ and NGA group $(\mathrm{OR}=1.83,95 \% \mathrm{CI} 1.06-3.16)$, and especially with the TGA-IVS group (OR $=2.35,95 \%$ CI $1.21-4.57)$.

\section{DISCUSSION}

This is the first epidemiological study of potential risk factors for conotruncal heart malformations in Egypt. We used the anatomical classification system of the BWIS to classify outflow tract anomalies into TGA and NGA groups. Unlike the population-based design of the BWIS, our data were from a single hospital and may not represent the total affected population. Moreover, the Egyptian and US populations differ in numerous ways that may influence CCVM: a high proportion of the Egyptian population resides in rural areas where farming is predominant; illiteracy levels are high; smoking cigarettes is extremely rare among females, and alcohol consumption is almost absent due to religious practices. Nevertheless, several findings are noteworthy, and their similarities to previous findings from other studies are striking.

\subsection{Study Population and Characteristics of the Cases}

In this study, there were equal proportions of TGA-IVS and TGA-VSD. This differs from the BWIS, in which TGA-IVS cases were nearly twice as common as TGAVSD. In addition, we found relatively higher proportions of DORV and pulmonary atresia-related phenoltypes compared to the BWIS. It is unclear if these are real differences or if they reflect referral, diagnosis, or other factors. Male predominance was found in the TGA and NGA groups, consistent with the BWIS and other reports $[3,11]$. In Egypt, testing of children with conotruncal heart malformations for $22 \mathrm{q} 11$ deletions is not routine, and no studies that we are aware of have reported its prevalence.

\subsection{Maternal Factors}

Results from this study and others $[12,13]$ suggest that maternal overt diabetes is associated with elevated risks for specific subgroups of TGA and NGA; yet, due to the small sample size in our study, these associations did not 
Table 4. Associations of environmental factors with conotruncal heart malformations.

\begin{tabular}{|c|c|c|c|c|c|c|c|c|c|c|c|c|}
\hline \multirow{2}{*}{ Diagnosis } & \multicolumn{3}{|c|}{$\begin{array}{l}\text { Mother's and/or father's } \\
\text { agricultural work }\end{array}$} & \multicolumn{3}{|c|}{ Raising animals } & \multicolumn{3}{|c|}{ Raising poultry } & \multicolumn{3}{|c|}{ Exposure to rodenticides } \\
\hline & No. $(\%)$ & OR & $95 \% \mathrm{CI}$ & No. $(\%)$ & OR & $95 \% \mathrm{CI}$ & No. (\%) & OR & $95 \% \mathrm{CI}$ & No. $(\%)$ & OR & $95 \% \mathrm{CI}$ \\
\hline All cases $(n=255)$ & $32(12.5)$ & 1.25 & $0.64 ; 2.53$ & $103(40.4)$ & 1.71 & $1.09 ; 2.70$ & $101(39.6)$ & 1.77 & $1.12 ; 2.80$ & $20(7.8)$ & 3.21 & $1.05 ; 13.15$ \\
\hline All TGA $(n=139)$ & $18(12.9)$ & 1.29 & $0.59 ; 2.84$ & $56(40.3)$ & 1.70 & $1.02 ; 2.85$ & $54(38.8)$ & 1.71 & $1.02 ; 2.88$ & $11(7.9)$ & 3.24 & $0.93 ; 14.26$ \\
\hline TGA VSD $(n=60)$ & $11(18.3)$ & 1.95 & $0.76 ; 4.82$ & $20(33.3)$ & 1.26 & $0.63 ; 2.49$ & $20(33.3)$ & 1.35 & $0.67 ; 2.67$ & $4(6.7)$ & 2.70 & $0.48 ; 14.92$ \\
\hline TGA IVS $(n=60)$ & $7(11.7)$ & 1.15 & $0.76 ; 4.82$ & $29(48.3)$ & 2.36 & $1.22 ; 4.56$ & $28(46.7)$ & 2.35 & $1.21 ; 4.57$ & $5(8.3)$ & 3.43 & $0.71 ; 17.83$ \\
\hline TGA DORV $(\mathrm{n}=16)$ & 0 & - & - & $7(43.8)$ & 1.96 & $0.58 ; 6.32$ & $6(37.5)$ & 1.61 & $0.45 ; 5.25$ & $2(12.5)$ & 5.39 & $0.44 ; 40.94$ \\
\hline All NGA $(n=116)$ & $14(12.1)$ & 1.19 & $0.51 ; 2.74$ & $47(40.5)$ & 1.72 & $1.00 ; 2.95$ & $47(40.5)$ & 1.83 & $1.06 ; 3.16$ & $9(7.8)$ & 3.18 & $0.86 ; 14.42$ \\
\hline NGA DORV $(\mathrm{n}=32)$ & $4(12.5)$ & 1.24 & $0.28 ; 4.25$ & $12(37.5)$ & 1.51 & $0.62 ; 3.57$ & $12(37.5)$ & 1.61 & $0.66 ; 3.82$ & $3(9.4)$ & 3.91 & $0.54 ; 24.18$ \\
\hline NGA TOF $(\mathrm{n}=76)$ & $9(11.8)$ & 1.17 & $0.43 ; 2.98$ & $32(42.1)$ & 1.84 & $0.99 ; 3.38$ & $32(42.1)$ & 1.96 & $1.05 ; 3.62$ & $5(6.6)$ & 2.66 & $0.55 ; 13.76$ \\
\hline Controls $(n=155)$ & $16(10.3)$ & 1 & Reference & $44(28.4)$ & 1 & Reference & $42(27.1)$ & 1 & Reference & $4(2.6)$ & 1 & Reference \\
\hline
\end{tabular}

reach statistical significance. However, the unadjusted diabetes associations are quite consistent with the results from the BWIS, in which the association was stronger in NGA (especially for TOF) than in TGA $[9,14,15]$. It has been suggested that diabetes mellitus alters the expression of genes regulating inflammatory responses and endothelial cell function, which might also be a mechanism resulting in poor fetal growth [16]. A recent study found that maternal diabetes also alters the expression of certain genes involved in the development and function of cardiac neural crest cells [17], which are essential for the development of the outflow tract.

In this study, the common cold but not fever was significantly associated with subtypes of TGA and NGA. Other studies found that maternal febrile diseases are associated with increased risk of certain heart defects [3, 18-20]. It is difficult to disentangle whether the fever or the underlying infection is the teratogenic factor; in some of the previously cited studies, the febrile illness was described as influenza-associated fever. The mechanicsm of teratogenesis in such cases may be related to altered apoptosis, which is involved in the normal development of the cardiac outflow tract and can be altered by infection or fever [8].

We did not find an association between advanced maternal age and increased prevalence of conotruncal malformations, as other studies have [21,22]. However, the relatively young age of mothers in our study inhibited such an analysis.

\subsection{Environmental Exposure}

Maternal exposure to rodenticide chemicals was associated with increased risk of conotruncal malformations in our study. These results are consistent with the BWIS in which exposure to rodenticides was associated with TGA
[10]. The coumarin derivatives used in many rodenticides have long biological half-lives, from 100 to 200 days. Therefore it is biologically plausible that exposure to rodenticides before conception or early during pregnancy could exert a potential effect on the fetus. Additionally, we found that raising animals, especially poultry, was associated with increased risk for both TGA and NGA groups, and Shaw et al. reported an association of increased risk of conotruncal heart malformations in California with maternal occupational exposures to insecticides [23]. A recent study in Texas, which measured the association between conotruncal malformations and urban/rural residence of mothers, found that TOF was most prevalent in rural areas, and the pattern was strongest using percentage of land in crops [24].

Neither tobacco smoking nor exposure to ETS was associated with conotruncal heart malformations in the present study. Previous reports have been inconclusive regarding such associations; for example, some studies found an association between paternal but not maternal smoking and conotruncal heart defects [25], while a recent study in California observed increased risk of TGA from maternal alcohol drinking but not from smoking [26]. In the BWIS, maternal cigarette smoking but not alcohol drinking was associated with the subset of TGA with VSD, but not with other types of conotruncal heart malformations [3].

\subsection{Methodological Considerations}

The exposure data in this study were self-reported, with a possibility of recall bias. In particular, mothers of cases might have over-reported acute illnesses during the pregnancy; when we controlled for treatment, the associations become statistically non-significant. However, we believe that no consistent pattern of over-reporting oc- 
curred in this study, since most of the variables from the questionnaire had non-significant case-control differences. We used an interview-based questionnaire to query exposure to pesticides among mothers. Although questionnaires alone usually do not provide adequate data for chemical classification [27], results from studies by the US Children's Environmental Health Center found that questionnaires were able to provide important information about the residential use of these chemicals [28]. They also provided information about exposure in households that would not have been captured by environmental biomonitoring [29].

Misclassification of CCVM in the present study is highly unlikely, as all diagnoses were confirmed by echocardiography or cardiac catheterization. Several of the findings, including maternal diabetes, male sex, blood disorders, and exposure to pesticides, are consistent with results from previous studies elsewhere. We used exact confidence intervals to reduce the problem of false inference from the small sample size. Finally, the findings from this study should be interpreted with caution since the sample size precluded adjustment for potential confounding factors.

\section{CONCLUSION}

Multi-center studies of conotruncal heart malformations should be encouraged to assess the risks from potential environmental risk factors, to employ biomarkers of exposure in order to shed further light on the possible doseresponse relationships, and to address the mechanisms of teratogenicity of diabetes and rodenticides. Such information could form the basis for public health interventions aimed at reducing the burden of CCVM globally.

\section{ACKNOWLEDGEMENTS}

The authors thank Dr. Nabiel Mikhail and his staff for data entry services for this study. We also thank the many interviewers who collected the data. Finally, we thank Dr. Fatma Meky for coordinating and supervising the recruitment of subjects and interviews for this study. The study was supported by grant \# BIO8-002-007 from the US-Egypt Joint Science and Technology Fund.

\section{REFERENCES}

[1] Rosamond, W., Flegal, K., Furie, K., et al. (2008) Heart disease and stroke statistics-2008 update: A report from the American Heart Association Statistics Committee and Stroke Statistics Subcommittee. Circulation, 117, 25-146. http://dx.doi.org/10.1161/CIRCULATIONAHA.107.1879 $\underline{98}$

[2] Hoffman, J.I. and Kaplan, S. (2002) The incidence of congenital heart disease. Journal of the American College of Cardiology, 39, 1890-1900.

http://dx.doi.org/10.1016/S0735-1097(02)01886-7
[3] Ferencz, C., Loffredo, C., Correa-Villasenor, A., et al. (1997) Genetic and environmental risk factors of major cardiovascular malformations: The Baltimore-Washington infant study 1981-1989. Future Publishing Company Inc., Bath.

[4] Loffredo, C.A. (2000) Epidemiology of cardiovascular malformations: Prevalence and risk factors. American Journal of Medical Genetics, 97, 319-325. http://dx.doi.org/10.1002/1096-8628(200024)97:4<319:: AID-AJMG1283>3.0.CO;2-E

[5] Botto, L.D., Correa, A. and Erickson, J.D. (2001) Racial and temporal variations in the prevalence of heart defects. Pediatrics, 107, 32.

http://dx.doi.org/10.1542/peds.107.3.e32

[6] Temtamy, S.A., Abdel Meguid, N., Mazen, I., et al. (1998) A genetic epidemiological study of malformations at birth in Egypt. Eastern Mediterranean Health Journal, 4, 252259.

[7] Pierpont, M.E., Basson, C.T., Benson Jr., D.W., et al. (2007) Genetic basis for congenital heart defects: Current knowledge: A scientific statement from the American Heart Association Congenital Cardiac Defects Committee, Council on Cardiovascular Disease in the Young: Endorsed by the American Academy of Pediatrics. Circulation, 115, 3015-3038.

[8] Jenkins, K.J., Correa, A., Feinstein, J.A., et al. (2007) Noninherited risk factors and congenital cardiovascular defects: Current knowledge: A scientific statement from the American Heart Association Council on Cardiovascular Disease in the Young: Endorsed by the American Academy of Pediatrics. Circulation, 115, 2995-3014.

http://dx.doi.org/10.1161/CIRCULATIONAHA.106.1832 16

[9] Loffredo, C.A., Wilson, P.D. and Ferencz, C. (2001) Maternal diabetes: An independent risk factor for major cardiovascular malformations with increased mortality of affected infants. Teratology, 64, 98-106. http://dx.doi.org/10.1002/tera.1051

[10] Loffredo, C.A., Silbergeld, E.K., Ferencz, C., et al. (2001) Association of transposition of the great arteries in infants with maternal exposures to herbicides and rodenticides. American Journal of Epidemiology, 153, 529-536. http://dx.doi.org/10.1093/aje/153.6.529

[11] Storch, T.G. and Mannick, E.E. (1992) Epidemiology of congenital heart disease in Louisiana: An association between race and sex and the prevalence of specific cardiac malformations. Teratology, 46, 271-276. http://dx.doi.org/10.1002/tera.1420460311

[12] Adams, M.M., Mulinare, J. and Dooley, K. (1989) Risk factors for conotruncal cardiac defects in Atlanta. Journal of the American College of Cardiology, 14, 432-442. http://dx.doi.org/10.1016/0735-1097(89)90199-X

[13] Lisowski, L.A., Verheijen, P.M., Copel, J.A., et al. (2010) Congenital heart disease in pregnancies complicated by maternal diabetes mellitus. An international clinical collaboration, literature review, and meta-analysis. Herz, 35, 19-26. http://dx.doi.org/10.1007/s00059-010-3244-3

[14] McCarter, R.J., Kessler, I.I. and Comstock, G.W. (1987) Is diabetes mellitus a teratogen or a coteratogen? Ameri- 
can Journal of Epidemiology, 125, 195-205.

[15] Ferencz, C., Rubin, J.D., McCarter, R.J., et al. (1990) Maternal diabetes and cardiovascular malformations: Predominance of double outlet right ventricle and truncus arteriosus. Teratology, 41, 319-326. http://dx.doi.org/10.1002/tera.1420410309

[16] Radaelli, T., Varastehpour, A., Catalano, P., et al. (2003) Gestational diabetes induces placental genes for chronic stress and inflammatory pathways. Diabetes, 52, 29512958. http://dx.doi.org/10.2337/diabetes.52.12.2951

[17] Kumar, S.D., Dheen, S.T. and Tay, S.S. (2007) Maternal diabetes induces congenital heart defects in mice by altering the expression of genes involved in cardiovascular development. Cardiovascular Diabetology, 6, 34. http://dx.doi.org/10.1186/1475-2840-6-34

[18] Botto, L.D., Lynberg, M.C. and Erickson, J.D. (2001) Congenital heart defects, maternal febrile illness, and multivitamin use: A population-based study. Epidemiology, 12, 485-490. http://dx.doi.org/10.1097/00001648-200109000-00004

[19] Zhang, J. and Cai, W.W. (1993) Association of the common cold in the first trimester of pregnancy with birth defects. Pediatrics, 92, 559-563.

[20] Shaw, G.M., Nelson, V., Carmichael, S.L., et al. (2002) Maternal periconceptional vitamins: Interactions with selected factors and congenital anomalies? Epidemiology, 13, 625-630. http://dx.doi.org/10.1097/00001648-200211000-00005

[21] Miller, A., Riehle-Colarusso, T., Siffel, C., et al. (2011) Maternal age and prevalence of isolated congenital heart defects in an urban area of the United States. American Journal of Medical Genetics Part A, 155A, 2137-2145. http://dx.doi.org/10.1002/ajmg.a.34130

[22] Long, J., Ramadhani, T. and Mitchell, L.E. (2010) Epidemiology of nonsyndromic conotruncal heart defects in Texas, 1999-2004. Birth Defects Research. Part A, Clinical and Molecular Teratology, 88, 971-979. http://dx.doi.org/10.1002/bdra.20724
[23] Shaw, G.M., Nelson, V., Iovannisci, D.M., et al. (2003) Maternal occupational chemical exposures and biotransformation genotypes as risk factors for selected congenital anomalies. American Journal of Epidemiology, 157, 475-484. http://dx.doi.org/10.1093/aje/kwg013

[24] Langlois, P.H., Jandle, L., Scheuerle, A., et al. (2010) Occurrence of conotruncal heart birth defects in Texas: A comparison of urban/rural classifications. Journal of Rural Health, 26, 164-174.

http://dx.doi.org/10.1111/j.1748-0361.2010.00278.x

[25] Wasserman, C.R., Shaw, G.M., O’Malley, C.D., et al. (1996) Parental cigarette smoking and risk for congenital anomalies of the heart, neural tube, or limb. Teratology, 53, 261-267.

http://dx.doi.org/10.1002/(SICI)1096-9926(199604)53:4< 261::AID-TERA9>3.0.CO;2-5

[26] Grewal, J., Carmichael, S.L., Ma, C., et al. (2008) Maternal periconceptional smoking and alcohol consumption and risk for select congenital anomalies. Birth Defects Research. Part A, Clinical and Molecular Teratology, 82, 519-526. http://dx.doi.org/10.1002/bdra.20461

[27] Sexton, K., Adgate, J.L., Eberly, L.E., et al. (2003) Predicting children's short-term exposure to pesticides: Results of a questionnaire screening approach. Environmental Health Perspectives, 111, 123-128. http://dx.doi.org/10.1289/ehp.5823

[28] Fenske, R.A., Bradman, A., Whyatt, R.M., et al. (2005) Lessons learned for the assessment of children's pesticide exposure: Critical sampling and analytical issues for future studies. Environmental Health Perspectives, 113, 1455 1462. http://dx.doi.org/10.1289/ehp.7674

[29] Bradman, A. and Whyatt, R.M. (2005) Characterizing exposures to nonpersistent pesticides during pregnancy and early childhood in the National Children's Study: A review of monitoring and measurement methodologies. Environmental Health Perspectives, 113, 1092-1099. http://dx.doi.org/10.1289/ehp.7769 